\title{
Initial surface film on magnesium metal: A characterization by X-ray photoelectron spectroscopy (XPS) and photocurrent spectroscopy (PCS)
}

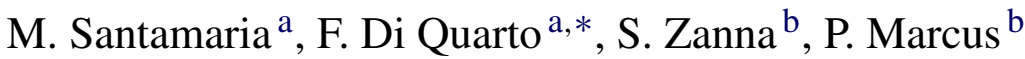 \\ ${ }^{a}$ Dipartimento di Ingegneria Chimica dei Processi e dei Materiali, Università di Palermo, Viale Delle Scienze, 90128 Palermo, Italy \\ ${ }^{\mathrm{b}}$ Laboratoire de Physico-Chimie des Surfaces, CNRS-ENSCP (UMR 7045), Ecole Nationale Supérieure de Chimie de Paris, \\ 11 rue Pierre et Marie Curie, 75005 Paris, France
}

Received 10 November 2006; received in revised form 4 January 2007; accepted 5 March 2007

Available online 12 March 2007

\begin{abstract}
A detailed investigation of the initial film grown on mechanically polished $\mathrm{Mg}$ electrodes has been carried out by $e x$ situ X-ray Photoelectron Spectroscopy (XPS) and in situ Photocurrent Spectroscopy (PCS), allowing to reach a detailed picture of the passive layer structure. The XPS data show that the films formed soon after mechanical treatment and immersion in aqueous electrolyte have a bilayer structure, consisting of an ultra-thin $\mathrm{MgO}$ inner layer $(\sim 2.5 \mathrm{~nm})$ and a $\mathrm{Mg}(\mathrm{OH})_{2}$ external layer. The thickness of the $\mathrm{Mg}(\mathrm{OH})_{2}$ layer is a function of immersion time and solution temperature. After mechanical treatment and immersion in aqueous solution at room temperature, the $\mathrm{MgO} / \mathrm{Mg}(\mathrm{OH})_{2}$ layer in some area of electrodes is so thin to allow an electron photoemission process from the Mg Fermi level to the electrolyte conduction band. Only internal photoemission processes are evidenced for $\mathrm{Mg}$ electrodes aged in $\mathrm{NaOH}$ at $80{ }^{\circ} \mathrm{C}$, due the formation of a thicker $\mathrm{Mg}(\mathrm{OH})_{2}$ layer. From anodic photocurrent spectra an optical band gap of $\sim 4.25 \mathrm{eV}$ has been estimated for $\mathrm{Mg}(\mathrm{OH})_{2}$, lower with respect to the optical gap of the corresponding anhydrous counterpart.
\end{abstract}

(C) 2007 Elsevier Ltd. All rights reserved.

Keywords: Magnesium; Magnesium hydroxide; XPS; PCS; Corrosion films

\section{Introduction}

Among light metals magnesium presents very interesting engineering properties owing to: its high specific stiffness, good machinability, high thermal conductivity, biocompatibility and easy recycling. These properties make magnesium very attractive for applications in automotive and aerospace industries, in electronics and sporting goods and hand-held products [1,2]. These potential advantages are counteracted by the poor corrosion and wear resistance of $\mathrm{Mg}$ and its alloys, due to the high chemical reactivity of $\mathrm{Mg}$ surface in presence of humidity or water, with formation of a poorly protective hydroxide layer having also detrimental effects on the coating processes $[3,4]$.

Previous investigations [3,5-9] have shown that the electrochemical behaviour of $\mathrm{Mg}$ electrodes is strongly dependent on anodizing parameters (electrolyte composition, $\mathrm{pH}$, current density, and/or voltage scanning rates, etc.). Depending on their

\footnotetext{
* Corresponding author.

E-mail address: diquarto@unipa.it (F. Di Quarto).
}

characteristics, electrolytes may act as (i) strong passivators (e.g. fluorides, chromates); (ii) moderate passivators (e.g. hydroxides, carbonates, borates, phosphates); (iii) moderate corrosion stimulators (e.g. sulphates, nitrates); or (iv) strong pitting agents (e.g. chlorides, bromides). The role of initial surface treatment on the anodization process has not been discussed, although it is very well known that the initial film could affect the kinetics of growth.

The mechanisms of growth as well as the nature of passivating layers formed on magnesium surfaces during anodization in aqueous solution are still open to debate. The formation of a porous thick film above an underlying crystalline barrier layer of $\mathrm{MgF}_{2}$ has been reported in Ref. [10] for anodization of $\mathrm{Mg}$ $(99.6 \%)$ in a complex industrial electrochemical bath (Dow 17) containing, among others, fluoride ions. Moreover, according to these authors, very high electric field strengths (in the order of $7 \times 10^{7} \mathrm{~V} \mathrm{~cm}^{-1}$ to $1 \times 10^{8} \mathrm{~V} \mathrm{~cm}^{-1}$ ) are expected across the barrier film during the growth under constant current density $\left(i_{\mathrm{cd}}\right)$ of $20 \mathrm{~mA} \mathrm{~cm}^{-2}$. The formation of an amorphous porous oxyhydroxide layer, having a generic composition $\mathrm{Mg}_{x+y / 2} \mathrm{O}_{x}(\mathrm{OH})_{y}$ was also suggested. 
Interestingly, the same authors [11] reported the presence of mixed oxy-hydroxide (hydrated) layers also by exposing a scratched $\mathrm{Mg}$ electrode in air both soon after the scratching and after very long ageing at room temperature. Moreover, the initial film thickness $\left(d_{\text {in }}=2.68 \mathrm{~nm}\right)$, estimated by XPS measurements, changed very little after months of exposure to air $\left(d_{\text {fin }}=3.09-3.13 \mathrm{~nm}\right)$ at room temperature although an increase of water molecules (from 1 to 3 ) into the film was reported for longer ageing times. However, these more recent results are partially conflicting with a previous study from the same laboratory [12] suggesting much thicker initial film in the order of 20-50 $\mathrm{nm}$ by exposure (15-60 $\mathrm{min}$ ) to air at room temperature $\left(25-30{ }^{\circ} \mathrm{C}\right)$ and relatively low humidity $(35-55 \%)$.

The sluggish kinetic of growth of magnesium oxides in air was confirmed in Ref. [13] where a study of $\mathrm{Mg}$ thermal oxidation in $\mathrm{O}_{2}$ atmosphere was performed in the range of temperature $25-400^{\circ} \mathrm{C}$. At $300^{\circ} \mathrm{C}$ an inverse logarithmic law fitted the kinetic of oxide growth for oxidation times up to $3600 \mathrm{~min}$, when a film thickness of $4.3 \mathrm{~nm}$ was estimated by XPS. The authors suggested that this finding is in agreement with the Cabrera-Mott model of film growth in presence of very high electric field and that the thickening of oxide limits the field strength and thus the oxide growth. At room temperature an oxide film thickness of $1.5 \mathrm{~nm}$ was estimated after $15 \mathrm{~min}$ of oxidation under $20 \mathrm{kPa} \mathrm{O}_{2}$ atmosphere in good agreement with the value of $1.9 \mathrm{~nm}$ estimated by Asami and Ono for the anhydrous $\mathrm{MgO}$ film [11].

As for the hydration process of $\mathrm{MgO}$ single crystal and thin films it has been recently reported [14] that this process, at room temperature and $80 \%$ relative humidity, is strongly influenced both by the crystallographic orientation and by the presence of defects at the oxide surface. However, as for the hydration of thin films, it was reported that, in the investigated conditions, the most important parameter in determining the hydration of the internal part of the films was their density so that for denser films the hydration process was limited to the surface.

Considering the limited information available on the nature of passivating layers on $\mathrm{Mg}$ in different solutions we have undertaken a detailed investigation and focussed our initial study on the characterization by different techniques (XPS, PCS) of initial films formed on magnesium in different conditions of surface preparation. It will be shown that the use of these techniques provides complementary information useful to better characterize both the nature of initial layer and possibly the structure of metal/oxide interface before and after anodizing process. The electrochemical behaviour and the kinetics of growth of anodic oxide film during anodization in aqueous solutions will be presented and discussed in a forthcoming paper.

\section{Experimental}

Pure magnesium (99.9\% from Goodfellow Metal) working electrodes have been used, as metallic foils (125-150 $\mu \mathrm{m}$ thickness) or rods ( $3 \mathrm{~mm}$ or $7 \mathrm{~mm}$ diameter). $\mathrm{Mg}$ foil have been covered with Lacomit stopping off, or in the case of rod electrodes embedded in Teflon cylinder and sealed with epoxy resin (Torr Seal Varian Ass.), leaving under solution exposure a con- stant geometrical area of $0.15 \mathrm{~cm}^{2}, 0.07 \mathrm{~cm}^{2}$ and $0.385 \mathrm{~cm}^{2}$, respectively.

Before anodization in $0.1 \mathrm{M}$ or $1 \mathrm{M} \mathrm{NaOH}$ solution, electrode surfaces have been subjected to mechanical polishing with 600 and 1200 emery paper (mechanically treated electrodes, MTE), followed by rinsing with distilled water and drying. In some cases the mechanical treatment was substituted by a scratching process by a knife edge in laboratory air. Ageing of mechanically treated electrodes was carried out at room temperature in distilled water or in $0.1 \mathrm{M} \mathrm{NaOH}$ solution at $80^{\circ} \mathrm{C}$ for $1 \mathrm{~h}$ or $2 \mathrm{~h}$.

Photocurrent spectroscopy (PCS) studies on initial films have been carried out in organic or aqueous electrolytes of different $\mathrm{pH}$. The employed aqueous electrolytes were: $1 \mathrm{M} \mathrm{NaOH}$

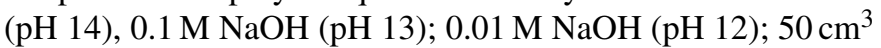
of $0.025 \mathrm{M} \mathrm{Na}_{2} \mathrm{~B}_{4} \mathrm{O}_{7}+18.3 \mathrm{~cm}^{3}$ of $0.01 \mathrm{M} \mathrm{NaOH}$ (buffer $\mathrm{pH}$ 10); $0.1 \mathrm{M} \mathrm{Na}_{2} \mathrm{SO}_{4}$ ( $\mathrm{pH}$ 6.15). All solutions have been prepared using analytical grade reagents at room temperature. As reference electrode saturated calomel (SCE: +0.244 V (NHE)), mercurous sulphate (MSE: +0.64 V (NHE)) or mercuric oxide ( $\mathrm{Hg} / \mathrm{HgO}:+0.098 \mathrm{~V}(\mathrm{NHE})$ ) electrodes have been used in aqueous solutions.

The PCS experiments in organic solution (propylene carbonate containing $0.1 \mathrm{M} \mathrm{LiClO}_{4}$ ) were carried out by using as received reagents and in aerated cell. In this case a quasi-reference SCE electrode separated by a fritt glass from the working electrode was used. The counter electrode was always a $\mathrm{Pt}$ wire. A quartz cell equipped with flat quartz windows for optical investigation was used for PCS experiments. The photoelectrochemical response of electrodes was obtained with the experimental set up described elsewhere [14]. Monochromatic irradiation was achieved by means of a lamp-monochromator-mechanical chopper system, coupled to a two phase lock-in amplifier (PAR 5206). The chopping frequency was $13 \mathrm{~Hz}$. Data have been acquired through an ana$\log$ /digital interface to a desk computer and corrected for the quantum emission of the light source (lamp and monochromator). Thus, on $y$-axis of photocurrent spectra a photocurrent yield in arbitrary units is reported.

MTE were analogously characterized by XPS measurements whilst a different ageing procedure was followed in the different environments in order to provide complementary information with respect to the PCS technique. Shorter ageing times $(15 \mathrm{~s}$, $30 \mathrm{~s}, 60 \mathrm{~s}, 300 \mathrm{~s}$ ) were used in order to keep the surface film sufficiently thin to get information from the metal/oxide interface.

A Thermo Electron Escalab 250 spectrometer with a monochromated $\mathrm{Al} \mathrm{K} \alpha$ radiation $(1486.6 \mathrm{eV})$ was used. The analyser pass energy was $100 \mathrm{eV}$ for survey spectra and $20 \mathrm{eV}$ for high resolution spectra. The spectrometer was calibrated against $\mathrm{Au} 4 \mathrm{f}_{7 / 2}$ at $84.1 \mathrm{eV}$. The following core levels were analysed: $\mathrm{Mg}$ 2p, O 1s, C 1s.

The photoelectron take-off angle (angle of the surface with the direction in which the photoelectrons are analysed) was $90^{\circ}$. Curve fitting of the spectra was performed with the Thermo Electron software Avantage. For the calculation of the surface oxide and hydroxide layers thickness, the inelastic mean free paths calculated by Tanuma et al. [15], and the photoemission cross sections calculated by Scofield [16] have been used. 


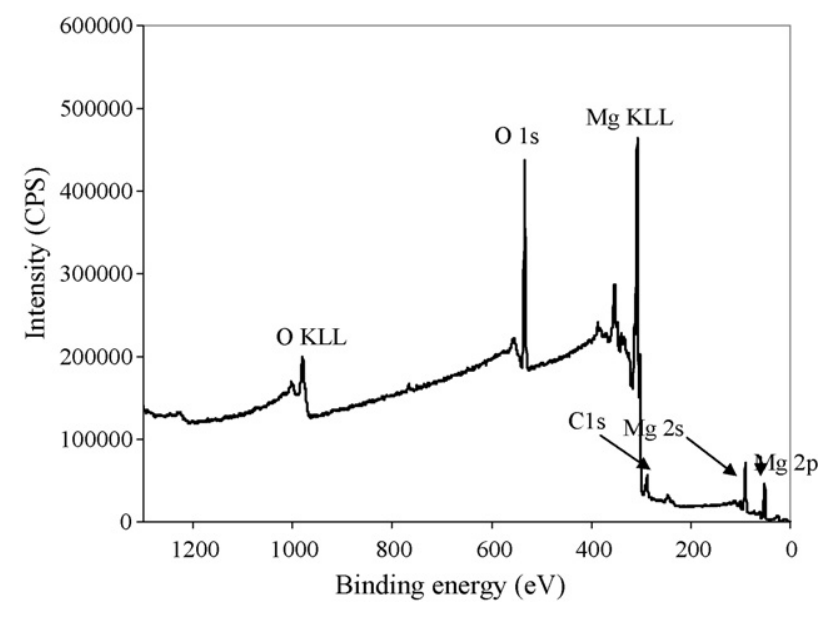

Fig. 1. XPS survey spectrum of the MTE surface.

\section{Results and discussion}

\subsection{Initial films}

The characterization of the initial film formed after different treatments was performed in vacuum by XPS and in solution by PCS. In the last case the initial characterization in aqueous solution was carried out at the open circuit potential, $U_{\mathrm{OC}}$, or at electrode potential values more cathodic or slightly anodic with respect to $U_{\mathrm{OC}}$.

\subsubsection{XPS characterization of mechanical treated electrodes}

To analyse the MTE surface, the Mg samples were mechanically polished without water and then analysed by XPS. The study of ageing in water was done for various times. The surface of the $\mathrm{Mg}$ samples was analysed after drying and transfer of the electrodes into the UHV chamber of the spectrometer. The survey spectrum recorded for the MT sample (Fig. 1) reveals the various elements present on the surface: $\mathrm{Mg}, \mathrm{O}, \mathrm{C}$. The high resolution $\mathrm{Mg} 2 \mathrm{p}$ and $\mathrm{O}$ 1s core level spectra are reported in Figs. 2 and 3, respectively, for the MTE prior to, and after immersion in distilled water for various lengths of time $(15 \mathrm{~s}, 30 \mathrm{~s}$, $1 \mathrm{~min}, 5 \mathrm{~min}$ ). The $\mathrm{Mg} 2 \mathrm{p}$ spectrum recorded after mechanical polishing shows a signal at $50.2 \mathrm{eV}$ emitted by the metal under a surface oxide layer, which indicates that this surface layer is extremely thin. The broad $\mathrm{Mg} 2 \mathrm{p}$ signal at higher binding energy (51.5 eV after charging effect correction) contains the contributions of magnesium oxide and magnesium hydroxide. A signal attributed to magnesium carbonate is also observed at higher binding energy $(52.2 \mathrm{eV}$ after correction for the charging effect). The $\mathrm{O} 1 \mathrm{~s}$ spectrum of the MTE (Fig. 3) shows peaks corresponding to $\mathrm{MgO}(531.7 \mathrm{eV}), \mathrm{Mg}(\mathrm{OH})_{2}(532.5 \mathrm{eV})$ and $\mathrm{MgCO}_{3}(533.2 \mathrm{eV})$. The binding energies for the hydroxide and carbonate species reported here have been corrected for charging effects. $\mathrm{Mg}$ is conductive and no charging effect is observed on the metallic magnesium signal. The $\mathrm{MgO}$ layer being thin and in direct contact with the metal, no significant charging effect is observed for the signals associated to this oxide. In contrast, a marked charging effect is noted for peaks associated with the magnesium hydroxide and the magnesium carbonate located in the outer part of the oxidized surface layer. This charging effect is found to increase with increasing thickness of the corrosion product layer. Thus, the binding energies reported in the text for magnesium hydroxide and magnesium carbonate have been corrected, using the position of the $\mathrm{C} 1 \mathrm{~s}$ signal from hydrocarbons in the contamination layer $(286 \mathrm{eV})$. In the $\mathrm{C} 1 \mathrm{~s}$ spectra (not shown), a signal attributed to magnesium carbonate was also observed (290.6 eV).

The XPS data reported above clearly show that the MTE surface is covered by a thin oxide layer $(\mathrm{MgO})$, with some magnesium hydroxide and magnesium carbonate. The thicknesses of the magnesium oxide and magnesium hydroxide layers have been calculated, using the $\mathrm{Mg} 2 \mathrm{p}$ and $\mathrm{O} 1 \mathrm{~s}$ intensities (peak areas). The thickness of the $\mathrm{MgO}$ layer is found to be $2.5 \mathrm{~nm}$, and the thickness of the outer layer of $\mathrm{Mg}$ hydroxide is $2.2 \mathrm{~nm}$. In the calculation it was assumed that the inner oxide layer and outer hydroxide layer cover the whole surface and are homogeneous. To confirm the assignment of the peaks, the ratio of intensities of the $\mathrm{O} 1 \mathrm{~s}$ and $\mathrm{Mg} 2 \mathrm{p}$ peaks associated to the magnesium hydroxide layer was measured and the $\mathrm{OH} / \mathrm{Mg}$ ratio was calculated. A value of $\approx 1.8$ was found, in reasonable agreement with the stoichiometry of $\mathrm{Mg}(\mathrm{OH})_{2}$.

The $\mathrm{Mg} 2 \mathrm{p}$ and $\mathrm{O}$ 1s spectra recorded after exposure of the MTE to high purity (Millipore) water are shown in Figs. 2 and 3, respectively, and the evolution of the oxide and hydroxide layer thickness is reported in Fig. 4. The data clearly show that the outer hydroxide layer grows, whereas the inner oxide layer remains present with the same composition and thickness. This
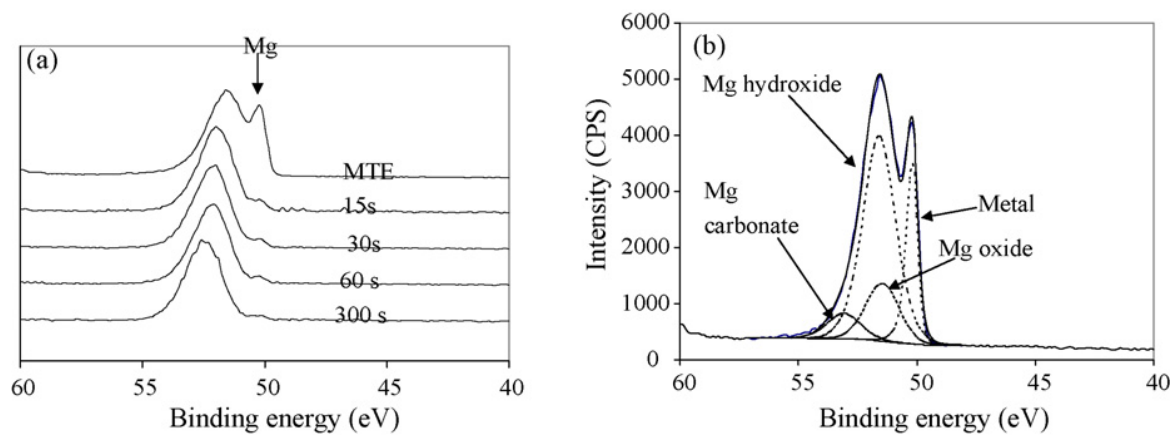

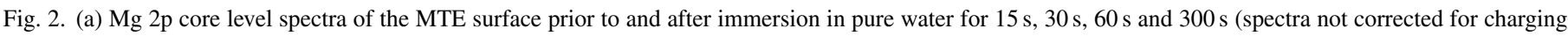
effects, see text) and (b) curve fitting of the $\mathrm{Mg} 2 \mathrm{p}$ region for the MTE surface. 

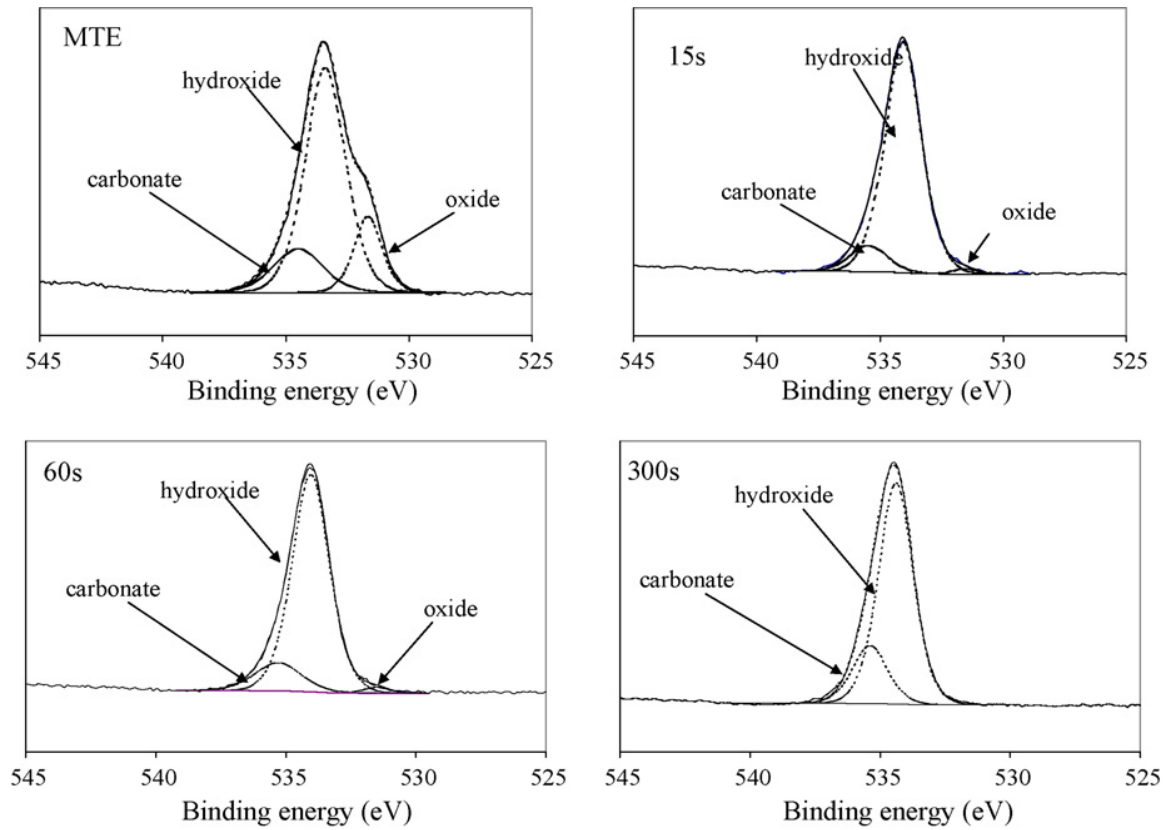

Fig. 3. Curve fitting of the $\mathrm{O} 1 \mathrm{~s}$ region for the MTE surface prior to and after immersion in pure water for $15 \mathrm{~s}, 60 \mathrm{~s}$ and $300 \mathrm{~s}$ (spectra not corrected for charging effects, see text).

is a major finding, because it proves that, in aqueous solution, a $\mathrm{Mg}$ hydroxide layer can grow while an ultra-thin $\mathrm{MgO}$ layer is maintained at the metal interface. After longer immersion times (300s) the $\mathrm{Mg}(\mathrm{OH})_{2}$ layer becomes thicker than about three times the attenuation length of the photoelectrons, and the oxide layer is no longer detected.

\subsubsection{PCS characterization of mechanical treated electrodes in aqueous solution}

Both mechanically polished (in absence of water) and blade scraped electrodes were investigated at $U_{\mathrm{OC}}$ (or at more cathodic potentials) soon after immersion in electrolytic solutions covering a large range of $\mathrm{pH}$ values $(6<\mathrm{pH}<14)$. No significant differences as a function of the initial treatment were observed in the photoelectrochemical behaviour of these electrodes: both the $U_{\mathrm{OC}}$ value and the shape of photocurrent spectra, soon after immersion in solution, were almost independent of the spe-

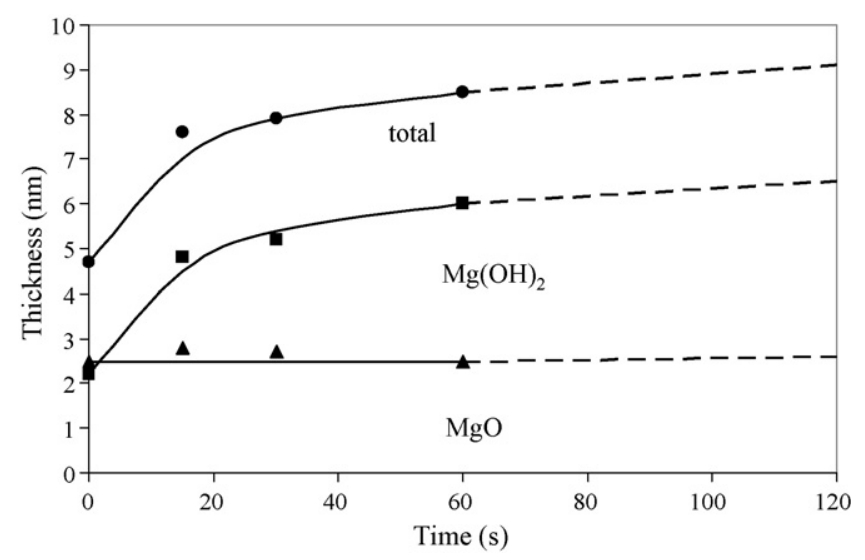

Fig. 4. Surface oxide and hydroxide layer thicknesses determined by XPS as function of the immersion time of magnesium in pure water. cific mechanical treatment. By taking into account that at $U_{\mathrm{OC}}$ cathodic photocurrent, due to electron photoemission processes (see below), was measured for any treatment, it is reasonable to attribute small differences in photocurrent values to slight differences in measured $U_{\mathrm{OC}}$ and possibly initial film thickness (see XPS analysis).

According to the XPS data reported above, a thin $\mathrm{MgO}$ oxide film $\left(d_{\mathrm{MgO}} \leq 25 \AA\right)$, covered with an increasingly thicker hydroxide layer, is formed on the MTE after immersion in aqueous solution. In the case of a compact bilayer the total oxide/hydroxide thickness after $15 \mathrm{~s}$ of immersion $(\geq 70 \AA)$ should be enough to avoid any external electron photoemission process from the metal Fermi level to the water conduction band [17]. Thus, a constant electron photoemission threshold should be expected as a consequence of the onset of an internal electron photoemission process from the metal Fermi level to the oxide/hydroxide conduction band according to equation:

$I_{\mathrm{ph}}^{0.5}=\operatorname{const}\left(h v-E_{\mathrm{th}}^{\mathrm{F}}\right)$

where $I_{\mathrm{ph}}$ is the photocurrent yield $\left(I_{\mathrm{ph}}=i_{\mathrm{ph}} / \Phi_{0}\right), \Phi_{0}(\lambda)$ is the photon flux at each wavelength and $E_{\mathrm{th}}^{\mathrm{F}}$ is the internal electron photoemission (Fowler) threshold.

In the case of a non-compact film, allowing direct access of electrolyte to the underlying thin $(\sim 30 \AA)$ oxide film, the possible onset of an external electron photoemission process must be taken into account as source of cathodic photocurrent. In this case, according to the theory, it is possible to write, for the emission photocurrent, the so-called "five half (5/2) power law", which gives the dependence of photocurrent from photon energy and electrode potential as [17-20]:

$I_{\mathrm{ph}}=\operatorname{const}\left(h v-h v_{0}-|e| U_{\mathrm{E}}\right)^{5 / 2}$ 
where $U_{\mathrm{E}}$ is the electrode potential measured with respect to a reference electrode, $h \nu_{0}$ the photoelectric threshold at zero electrode potential (changing with reference electrode) and $h v$ is the photon energy in $\mathrm{eV}$.

At constant potential the photocurrent yield can be expressed as

$\left(I_{\mathrm{ph}}\right)^{0.4}=\operatorname{const}\left(h v-E_{\mathrm{th}}\right)$

where $E_{\mathrm{th}}=h v_{0}+|e| U_{\mathrm{E}}$ is the measured photoemission threshold, dependent on the imposed electrode potential. It follows that a change in the photoemission threshold versus potential of $1 \mathrm{eV} / \mathrm{V}$ is expected.

The possibility of band to band optical transitions has been neglected, considering that cathodic photocurrent at photon energy much less than the band gap of $\mathrm{MgO}\left(E_{\mathrm{g}}=7.8-8.7 \mathrm{eV}\right.$, see Refs. [21,22] $)$ or $\mathrm{Mg}(\mathrm{OH})_{2}\left(E_{\mathrm{g}}=4.25 \mathrm{eV}\right.$, see below $)$ was measured at $U_{\mathrm{OC}}$ or more cathodic potentials.

Fig. 5 shows the photocurrent spectrum, in the long wavelengths region, recorded at constant potential $U_{\mathrm{E}}=-1.94 \mathrm{~V}$ (MSE) (more cathodic than the respective $U_{\mathrm{OC}}$ potential), for a freshly prepared MTE at the lowest investigated $\mathrm{pH}$ value. At constant electrode potential an almost identical photoemission threshold was measured for MTE electrodes in largely different solution $\mathrm{pH}$ values $(6<\mathrm{pH}<14)$ when the photocurrent yield, $I_{\mathrm{ph}}$, was plotted according to $1 / 2$ power law (internal photoemission) or as a " $5 / 2$ power law" (external photoemission). Obviously larger threshold values are obtained by extrapolating according to the $1 / 2$ power law.

On the other hand in Fig. 6 we report the cathodic photocurrent spectrum at electrode potential slightly more anodic than the previous one and for $\mathrm{pH} 12$. The variation of photoemission threshold with electrode potential agrees with the hypothesized occurrence of an external photoemission process. By assuming that the electron photoemission process occurs from the metal Fermi level to the bottom of the conduction band [18] of liquid water, $E_{\mathrm{H}_{2} \mathrm{O}}^{\mathrm{C}}$, this last level can be estimated (with respect to the vacuum) according to the equation:

$E_{\mathrm{H}_{2} \mathrm{O}}^{\mathrm{C}}=E_{\text {th }}-|e| U_{\mathrm{E}}(\mathrm{ref})-|e| U_{\mathrm{E}, \mathrm{ref}}(\mathrm{vac})$

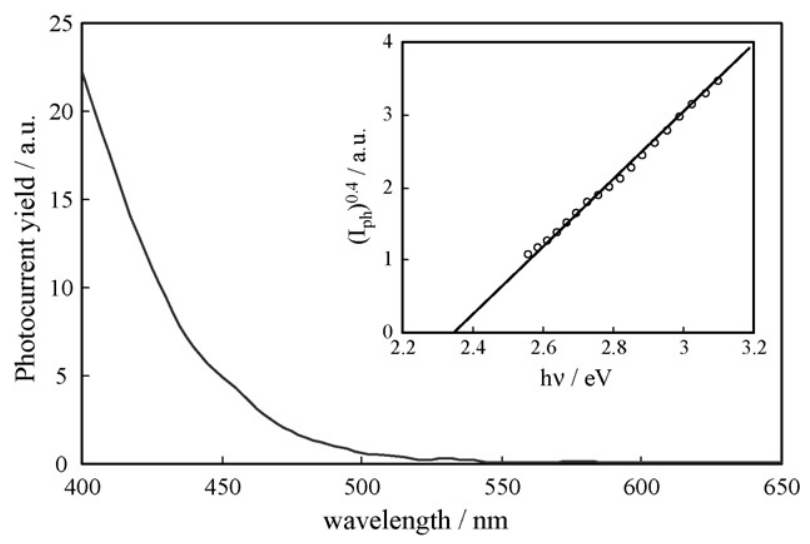

Fig. 5. Photocurrent spectrum relating to $\mathrm{Mg}$ after mechanical treatment recorded by polarizing the electrode at $-1.94 \mathrm{~V}$ (MSE) in $0.1 \mathrm{M} \mathrm{Na}_{2} \mathrm{SO}_{4}(\mathrm{pH}$ 6.15). Inset: estimate of the external photoemission threshold.

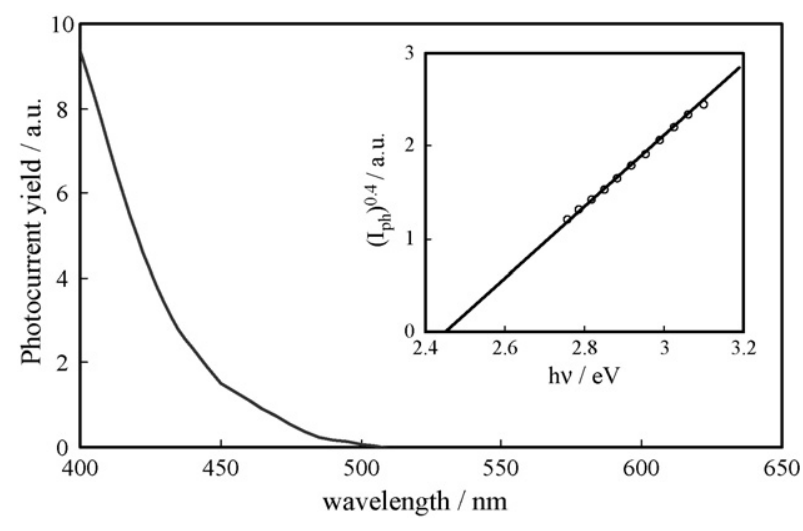

Fig. 6. Photocurrent spectrum relating to $\mathrm{Mg}$ after mechanical treatment recorded by polarizing the electrode at $U_{\mathrm{OC}}=-1.81 \mathrm{~V}(\mathrm{MSE})$ in $0.01 \mathrm{M} \mathrm{NaOH}$ (pH 12). Inset: estimate of the external photoemission threshold.

where $E_{\mathrm{th}}$ is the photocurrent emission threshold calculated according to Eq. (2b), $U_{\mathrm{E}}$ is the electrode potential with respect to a reference electrode, and $U_{\mathrm{E}, \mathrm{ref}}(\mathrm{vac})$ is the reference electrode potential with respect to the vacuum. A value of $4.60 \mathrm{~V}$ has been assumed on the vacuum scale for the NHE according to different authors [23].

By averaging for different $\mathrm{pH}, E_{\mathrm{th}}$ and $U_{\mathrm{E}}$ values, an almost constant $E_{\mathrm{H}_{2} \mathrm{O}}^{\mathrm{C}}$ value close to $-1 \mathrm{eV}$ was obtained, as reported in Fig. 7. This value agrees quite well with previously reported value $(-1 \pm 0.1 \mathrm{eV})[17,19,20,24]$, making reasonable the hypothesis that an external photoemission process is responsible for the onset of cathodic photocurrent at mechanically treated or blade scraped electrodes polarized at $U_{\mathrm{OC}}$ soon after immersion into aqueous solution.

\subsubsection{PCS characterization of mechanical treated electrodes in organic solution}

In order to test further the previously suggested hypothesis, we decided to carry out a series of experiments in non-aqueous solution. This choice was dictated by the desire to exploit a larger range of electrode potentials and to avoid film growth on $\mathrm{Mg}$ in the electrolyte.

The photoelectrochemical behaviour of MTE Mg electrodes was investigated in propylene carbonate solution containing $0.1 \mathrm{M} \mathrm{LiClO}_{4}$. The organic solvent and lithium salt could be

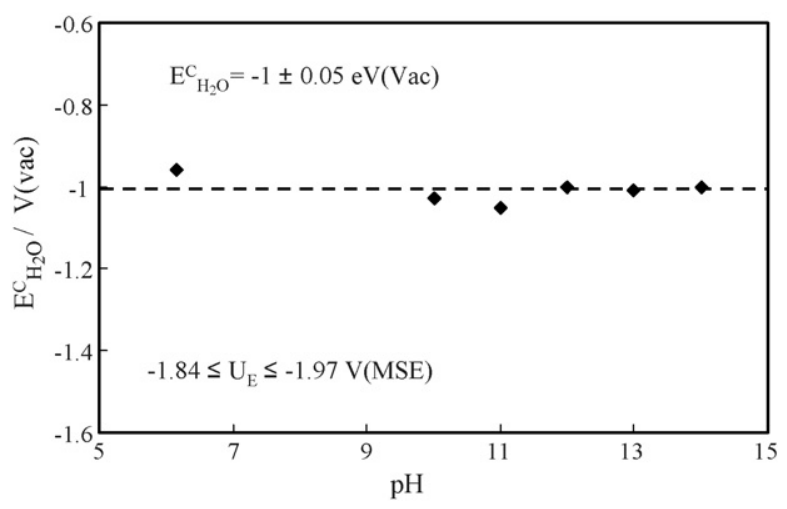

Fig. 7. Estimated energy levels of water conduction band from external photoemission data as a function of solution $\mathrm{pH}$. 


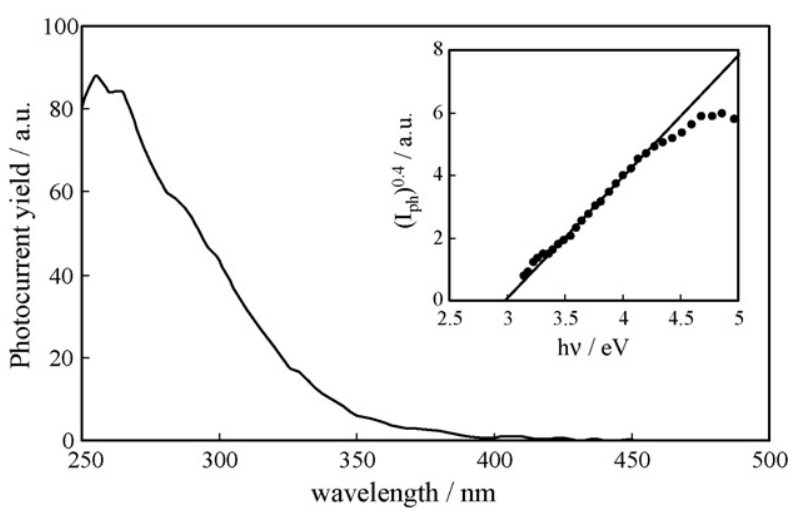

Fig. 8. Photocurrent spectrum relating to $\mathrm{Mg}$ after mechanical treatment recorded by polarizing the electrode at $-1.15 \mathrm{~V}$ (SCE) in $0.1 \mathrm{M} \mathrm{LiClO}_{4}$ propylene carbonate electrolyte. Inset: estimate of the external photoemission threshold.

used as received, without any further precaution in aerated cell, provided that the presence of electrons scavenger $\left(\mathrm{O}_{2}\right)$ does not affect the experiment. The large stability window of employed solvent in the cathodic region allowed to span a large range of electrode potentials starting from $U_{\mathrm{OC}}$. This last value was around $-1.1 \mathrm{~V}$ (SCE) in these conditions.

In Figs. 8 and 9 we report the cathodic photocurrent spectra of MTE Mg electrodes at two different electrode potentials covering the exploited electrode potentials range. As evidenced in the figures (see inset) the photocurrent yield plotted according to the 5/2 law (see Eq. (2)) gives an onset photocurrent threshold value strongly dependent on the electrode potential. The threshold values are reported as a function of $U_{\mathrm{E}}$ in Fig. 10. A slope of about $1 \mathrm{eV} / \mathrm{V}$ was derived, in agreement with the theoretical expectation [18]. Further support in favour of photoemission process comes out from the $\left(I_{\mathrm{ph}}\right)^{0.4}$ versus $U_{\mathrm{E}}$ plots at different wavelengths $(\lambda=450 \mathrm{~nm}, 400 \mathrm{~nm})$ (see Fig. 11) showing a zero photocurrent potential value which shifts with photon energy (about $1 \mathrm{~V} / \mathrm{eV}$ ) as foreseen from the theory (see Eq. (2)) [18].

From the data of Figs. 8-11 it is possible to locate the bottom of the conduction band of the organic solvent (or the energy level

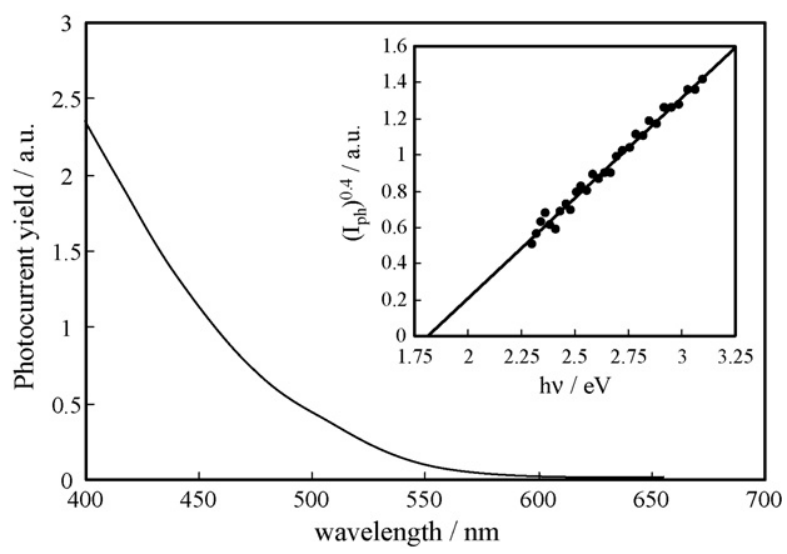

Fig. 9. Photocurrent spectrum relating to $\mathrm{Mg}$ after mechanical treatment recorded by polarizing the electrode at $-2.40 \mathrm{~V}$ (SCE) in $0.1 \mathrm{M} \mathrm{LiClO}_{4}$ propylene carbonate electrolyte. Inset: estimate of the external photoemission threshold.

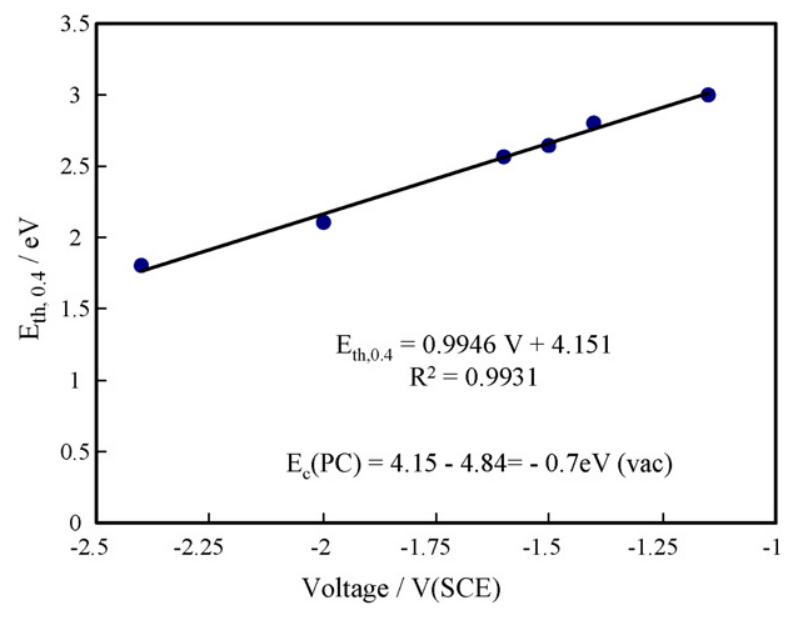

Fig. 10. External photoemission threshold as a function of electrode potential. Sol: $0.1 \mathrm{M} \mathrm{LiClO}_{4}$ in propylene carbonate.

of photoemitted electron in propylene carbonate) by subtracting to the photoemission threshold $(4.15 \mathrm{eV})$, at zero electrode potential, the Fermi energy level of SCE measured with respect to the vacuum $(-4.84 \mathrm{eV})$. It comes out that the bottom of the conduction band of propylene carbonate is located at about $-0.7 \mathrm{eV}$ with respect to the vacuum (see also Fig. 21b). However, such a value incorporates an uncertainty on the potential drop at the organic solvent/SCE junction.

The value derived for the conduction band bottom edge of propylene carbonate compares quite well with corresponding values reported in Ref. [18] for other organic solvents and it allows to get an estimate for the Volta potential difference $(\cong-0.3 \mathrm{~V}$ ) between $\mathrm{Mg}$ and propylene carbonate at zero charge.

As for the nature of electrons scavenger in organic (PC) solution, it seems reasonable to assign such a role to oxygen. In fact it has been reported in the literature [25] that a quite large $\left(\sim 100 \mu \mathrm{A} \mathrm{cm}^{-2}\right)$ cathodic current is measured in $1 \mathrm{M} \mathrm{LiClO}_{4}$ propylene carbonate solution owing to the reduction of dissolved $\mathrm{O}_{2}$ to $\mathrm{O}_{2}{ }^{\bullet-}$ radical species, at electrode potential of $-0.50 \mathrm{~V}$ (SCE) aqueous.

We like to mention that in the same electrolyte a cathodic limiting current density of $\sim 50 \mu \mathrm{A} \mathrm{cm}^{-2}$, at potentials more cathodic than $-1.50 \mathrm{~V}$ (SCE), was measured on a gold electrode

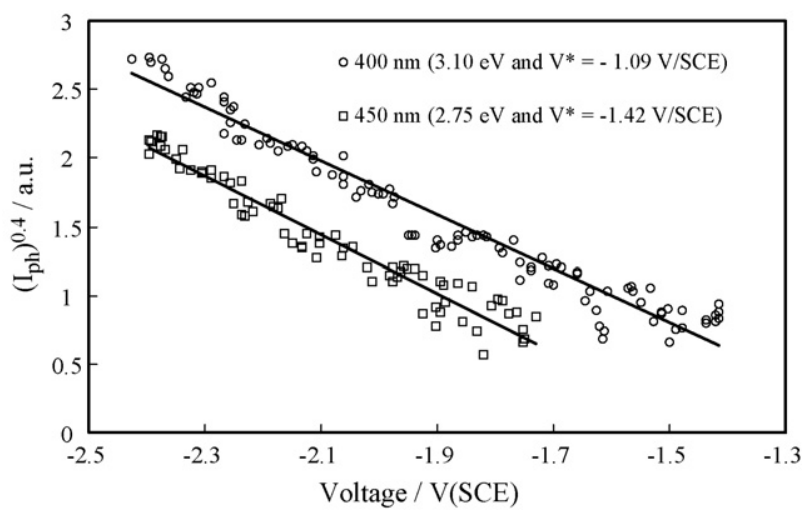

Fig. 11. $\left(I_{\mathrm{ph}}\right)^{0.4}$ vs. $U_{\mathrm{E}}$ plots for mechanical treated $\mathrm{Mg}$, recorded by scanning the electrode potential at $10 \mathrm{mV} \mathrm{s}^{-1}$. Sol: $0.1 \mathrm{M} \mathrm{LiClO}_{4}$ in propylene carbonate. 
in a linear potential sweep performed at $20 \mathrm{mV} \mathrm{s}^{-1}$. The value of the limiting current density was slightly decreasing by repetitive scans and, according to the above mentioned findings, it could be attributed to an oxygen reduction process.

\subsection{Aged films}

A study of the ageing effects on MTE electrodes was carried out prior to the anodic oxidation process in order to get information on the modifications of MTE surface occurring in different conditions. We have chosen, as ageing processes: (a) immersion of MTE in distilled water at room temperature for variable times (up to $2 \mathrm{~h}$ ); (b) immersion in $0.1 \mathrm{M} \mathrm{NaOH}$ solution at $80^{\circ} \mathrm{C}$ for variable times $(0.5 \mathrm{~h}, 1 \mathrm{~h}$ and $2 \mathrm{~h})$.

In the case of ageing in water at room temperature, no appreciable changes were observed in the photocurrent spectra apart, possibly, a small decrease in the measured photocurrent intensities in the case of aged electrodes when compared with non-aged electrodes at the same potential.

As for the photoemission threshold, a variable threshold was measured, by plotting the photocurrent yield according to Eq. (2), in very good agreement with the expected $1 \mathrm{eV} / \mathrm{V}$ dependence, provided that the measured spectra were obtained at electrode potentials always more cathodic than the $U_{\mathrm{OC}}$ value. This is evidenced in Figs. 12 and 13, where the photocurrent spectra and photoemission threshold values for aged $(1 \mathrm{~h}, 2 \mathrm{~h}$ in $\mathrm{H}_{2} \mathrm{O}$ at room temperature) electrodes polarized in $0.1 \mathrm{M} \mathrm{NaOH}$ solution at different electrode potentials are reported. Also in this case, experimental values of $E_{\mathrm{H}_{2} \mathrm{O}}^{\mathrm{C}}$ are close to $-1( \pm 0.1) \mathrm{eV}$, in good agreement with previous ones. By exploiting a larger range of electrode potentials for both $1 \mathrm{~h}$ and $2 \mathrm{~h}$ of ageing in $\mathrm{H}_{2} \mathrm{O}$, a quite good agreement between theory and experimental results was observed (see Fig. 14). In aerated aqueous solution it seems reasonable to suggest as scavengers of photoemitted electron the water molecules in solution, as suggested in Ref. [18], although the capture of electrons by dissolved oxygen cannot be excluded.

If we assume that a thick hydroxide layer is formed during ageing in water (as shown by the XPS data) our results seem to

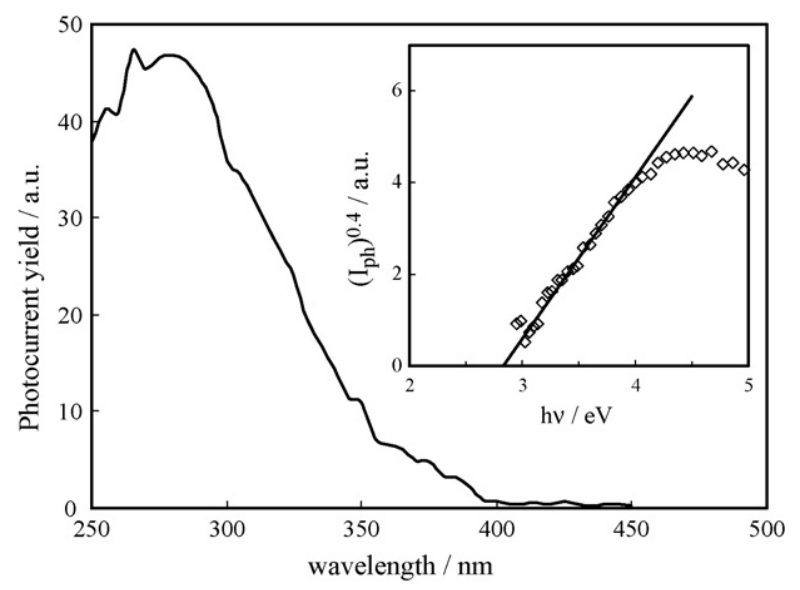

Fig. 12. Photocurrent spectrum relating to $\mathrm{Mg}$ after mechanical treatment and immersion in distilled water for $1 \mathrm{~h}$, recorded by polarizing the electrode at $-0.9 \mathrm{~V}(\mathrm{Hg} / \mathrm{HgO})$ in $0.1 \mathrm{M} \mathrm{NaOH}$. Inset: estimate of the external photoemission threshold.

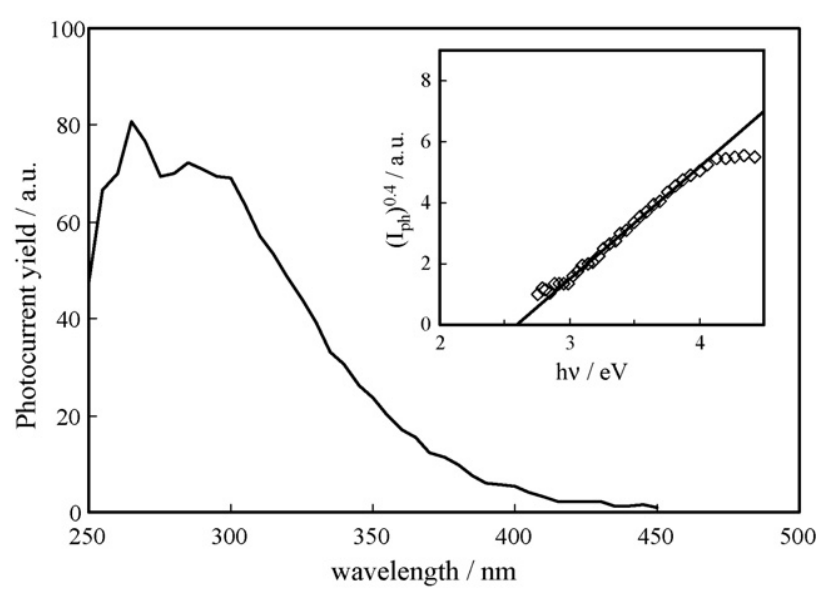

Fig. 13. Photocurrent spectrum relating to $\mathrm{Mg}$ after mechanical treatment and immersion in distilled water for $2 \mathrm{~h}$, recorded by polarizing the electrode at $-1.2 \mathrm{~V}(\mathrm{Hg} / \mathrm{HgO})$ in $0.1 \mathrm{M} \mathrm{NaOH}$. Inset: estimate of the external photoemission threshold.

suggest that this layer must be very permeable to the solution and that any barrier layer (e.g. $\mathrm{MgO}$ ) eventually still present on the $\mathrm{Mg}$ surface must be very thin. The XPS data showing the presence of an underlying layer of $\mathrm{MgO}$ after shorter ( $\leq 60 \mathrm{~s}$ ) immersion times in $\mathrm{H}_{2} \mathrm{O}$ underneath a thicker and growing $\mathrm{Mg}(\mathrm{OH})_{2}$ layer supports our hypothesis of porous external layer above a very thin barrier $\mathrm{MgO}$ film.

For $\mathrm{Mg}$ electrodes aged in $0.1 \mathrm{M} \mathrm{NaOH}$ at $80^{\circ} \mathrm{C}$, appreciable differences were observed both in photocurrent spectra and photoemission threshold values. More importantly the photoemission threshold value appeared almost independent of the electrode potential in a relatively large range of electrode potentials $(0.4 \mathrm{~V})$ when the photocurrent yield was plotted according to Eq. (1), valid for internal electron photoemission (Fowler) process. This is evidenced in Figs. 15 and 16 where the cathodic photocurrent spectra for an aged ( $1 \mathrm{~h}$ immersion in $0.1 \mathrm{M} \mathrm{NaOH}$ solution at $80^{\circ} \mathrm{C}$ ) $\mathrm{Mg}$ electrode at two largely different potentials are reported. In the insets of both figures, the Fowler plot is reported showing that an almost identical threshold value ( $E_{\mathrm{th}}^{\mathrm{F}} \cong 2.2 \mathrm{eV}$ ) is measured for the two polarization potentials.

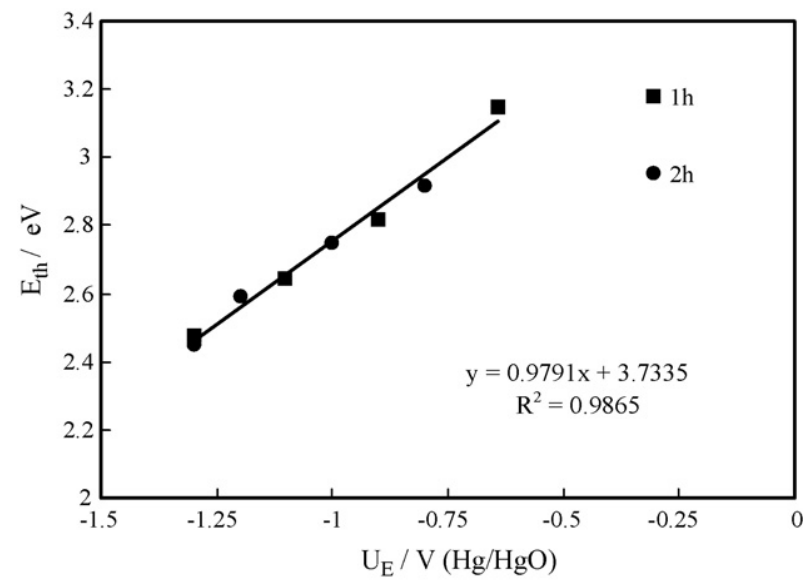

Fig. 14. External photoemission threshold as a function of electrode potential for MTE electrodes aged in distilled $\mathrm{H}_{2} \mathrm{O}$ at room temperature. 


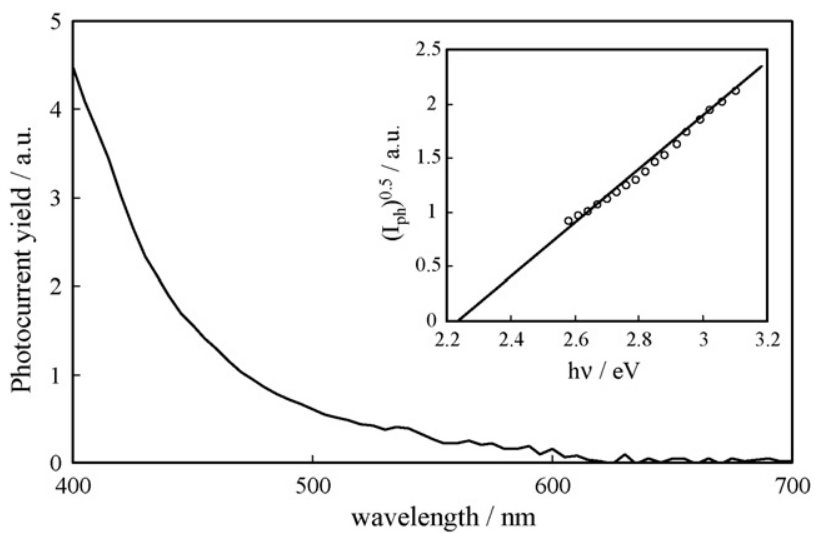

Fig. 15. Photocurrent spectrum relating to $\mathrm{Mg}$ after mechanical treatment and immersion in $0.1 \mathrm{M} \mathrm{NaOH}$ at $80^{\circ} \mathrm{C}$ for $1 \mathrm{~h}$, recorded by polarizing the electrode at $-1.93 \mathrm{~V}$ (MSE) in $0.1 \mathrm{M} \mathrm{NaOH}$ at room temperature. Inset: estimate of the Fowler photoemission threshold.

This finding suggests that after $1 \mathrm{~h}$ of ageing in alkaline solution at $80^{\circ} \mathrm{C}$ a relatively thick and compact film is formed on the $\mathrm{Mg}$ electrode, which is able to block any direct tunnelling of photoelectrons trough the film to the water solution. We have to mention that even after shorter ageing time $(30 \mathrm{~min}$ in $0.1 \mathrm{M} \mathrm{NaOH}$ at $\left.80^{\circ} \mathrm{C}\right)$ similar Fowler threshold value $(2.15 \mathrm{eV}$ at $-1.21 \mathrm{~V}(\mathrm{MSE}))$ was measured.

As for the nature of this film the PCS analysis suggests the formation of a thick $\mathrm{Mg}(\mathrm{OH})_{2}$ layer impervious to the solution, although the presence of a very thin (and transparent to photoelectrons) $\mathrm{MgO}$ layer at the metal/oxide interface cannot be excluded (see XPS data).

Further support to this interpretation comes out from the data of Figs. 17 and 18 showing a comparison of the cathodic spectra for two MTE Mg electrodes with and without ageing treatment in alkaline solution but at the same electrode potential. In Fig. 17 we report the cathodic photocurrent spectrum, at $U_{\mathrm{OC}}$ potential, of a MTE Mg electrode aged for $2 \mathrm{~h}$ at $80^{\circ} \mathrm{C}$ in alkaline solution. In this case an internal photoemission process

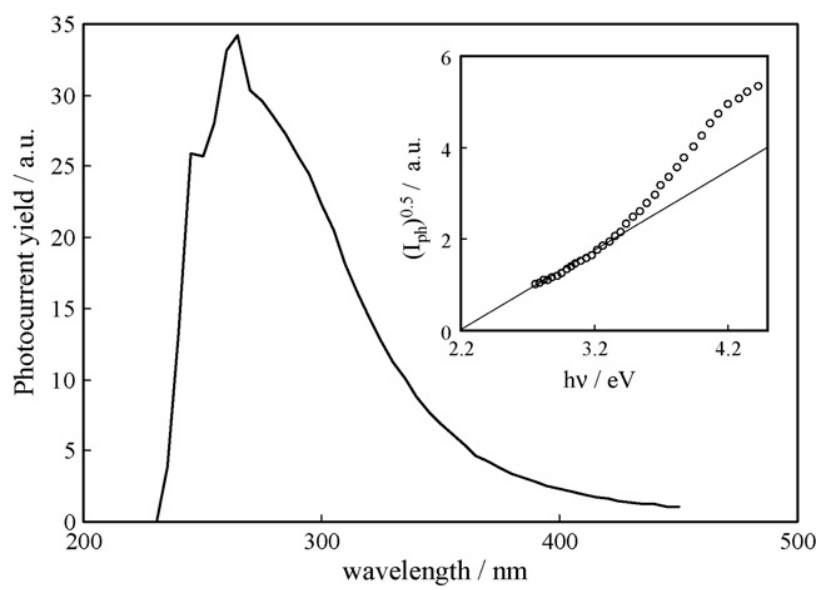

Fig. 16. Photocurrent spectrum relating to $\mathrm{Mg}$ after mechanical treatment and immersion in $0.1 \mathrm{M} \mathrm{NaOH}$ at $80^{\circ} \mathrm{C}$ for $1 \mathrm{~h}$, recorded by polarizing the electrode at $-1.53 \mathrm{~V}$ (MSE) in $0.1 \mathrm{M} \mathrm{NaOH}$ at room temperature. Inset: estimate of the Fowler photoemission threshold.

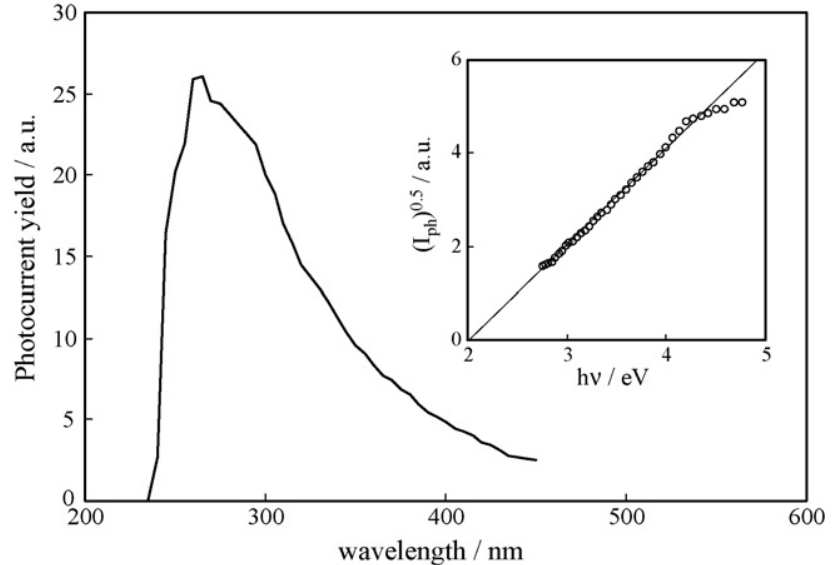

Fig. 17. Photocurrent spectrum relating to $\mathrm{Mg}$ after mechanical treatment and immersion in $0.1 \mathrm{M} \mathrm{NaOH}$ at $80^{\circ} \mathrm{C}$ for $2 \mathrm{~h}$, recorded by polarizing the electrode at $-1.40 \mathrm{~V}(\mathrm{MSE})$ in $0.1 \mathrm{M} \mathrm{NaOH}$ at room temperature. Inset: estimate of the Fowler photoemission threshold.

is occurring; as suggested by the much lower photoemission threshold value $\left(E_{\mathrm{th}}^{\mathrm{F}}=2.05 \mathrm{eV}\right)$. Such a value is not compatible with a direct photoemission process from the Mg Fermi level to the water conduction band level. The slightly lower Fowler threshold value, not too far however from those obtained in Figs. 15 and 16, could be attributed to the formation of a more crystalline hydroxide layer. For comparison we report in Fig. 18 the cathodic photocurrent spectrum, at the same potential, of a MTE Mg electrode immersed directly into $0.1 \mathrm{M} \mathrm{NaOH}$ solution showing an external photoemission threshold near to $2.85 \mathrm{eV}$, posing $E_{\mathrm{H}_{2} \mathrm{O}}^{\mathrm{C}}=-1.0 \mathrm{eV}$ in agreement with previous results.

According to the results previously described it is possible to derive some preliminary conclusions on the nature of initial films formed on Mg electrode as a function of MTE and ageing:

(a) Regardless of the initial mechanical treatment (knife scraping or mechanical polishing) the magnesium electrode soon after immersion in solution at open circuit potential $\left(U_{\mathrm{OC}}\right)$ is covered by an initial oxide layer of very limited thickness,

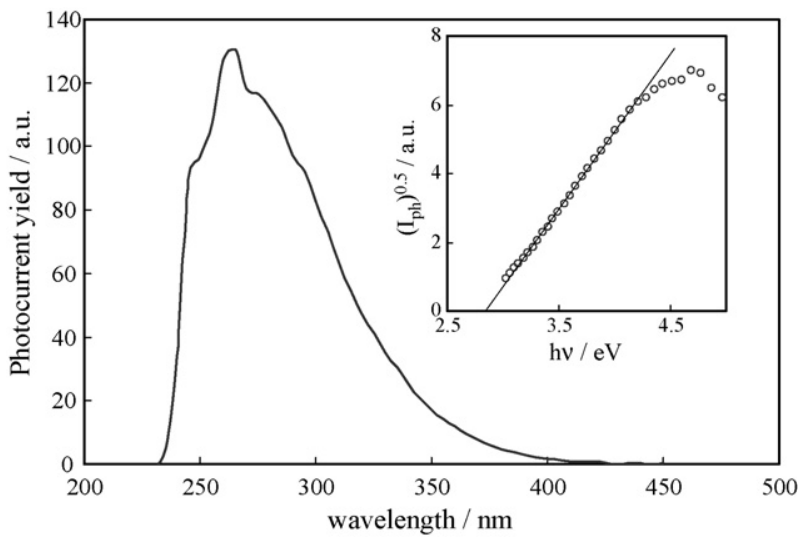

Fig. 18. Photocurrent spectrum relating to $\mathrm{Mg}$ after mechanical treatment, recorded by polarizing the electrode at $-1.40 \mathrm{~V}$ (MSE) in $0.1 \mathrm{M} \mathrm{NaOH}$ at room temperature. Inset: estimate of the external photoemission threshold. 


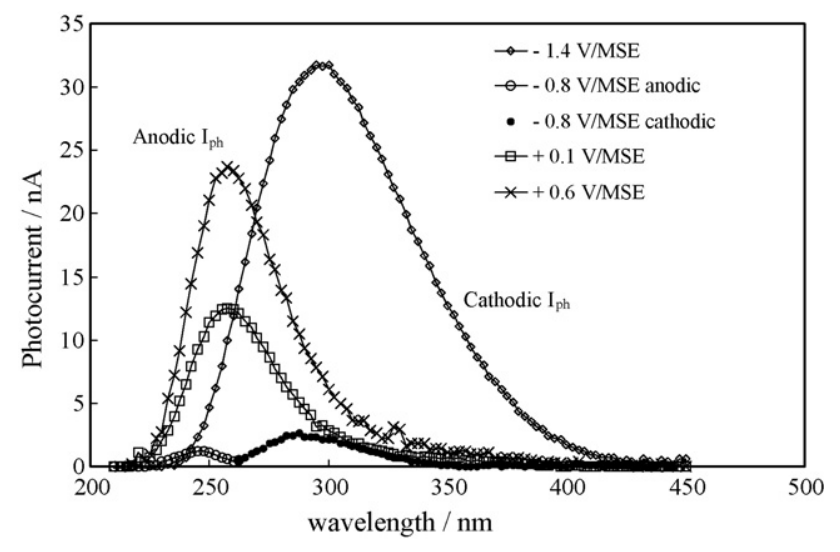

Fig. 19. Raw photocurrent spectra relating to $\mathrm{Mg}$ after mechanical treatment, recorded by polarizing the electrode at different electrode potentials in $0.1 \mathrm{M}$ $\mathrm{NaOH}$. At $U_{\mathrm{E}}=-0.8 \mathrm{~V}$ (MSE) anodic $(\lambda<270 \mathrm{~nm})$ and cathodic $(\lambda>270 \mathrm{~nm})$ photocurrent was recorded.

at least in some region of surface area, sufficiently thin $\left(d_{\mathrm{ox}} \leq 3.0 \mathrm{~nm}\right)$ to allow a direct tunnelling process from the metal to the solution.

(b) The film formed on MTE at $U_{\mathrm{E}}=-1.4 \mathrm{~V}$ (MSE) and high $\mathrm{pH}$ values $(\mathrm{pH} 13)$ is still sufficiently thin to allow an external photoemission process. Ageing of MT Mg electrodes in pure water and at room temperature does not seem to block the electron photoemission process from the metal Fermi level directly to the water conduction band.

(c) The external photoemission process is forbidden on MTE aged at high temperature $\left(80^{\circ} \mathrm{C}\right.$ in $\mathrm{NaOH}$ solution) owing to the formation of a thicker, impervious to photoelectrons, $\mathrm{Mg}(\mathrm{OH})_{2}$ layer. In this case an internal photoemission threshold (Fowler threshold) around $2.15 \pm 0.1 \mathrm{eV}$ has been measured for different ageing times and electrode potentials. In this case according to the schematic energy levels picture reported below (see Fig. 21b) it seems quite reasonable to assume that the photoemitted electrons thermalized at the conduction band level are consumed for a reduction process involving water.

\subsection{Anodic films}

After characterization at $U_{\mathrm{OC}}$, a series of experiments were carried out by stepping the electrode potential toward anodic direction and recording the photocurrent spectra at each electrode potential. The behaviour of photocurrent spectra for MT electrodes as a function of anodic potential values are summarized in Fig. 19, showing different spectra from $U_{\mathrm{OC}}$ until $+0.6 \mathrm{~V}$ (MSE). At electrode potentials near $-0.8 \mathrm{~V}$ (MSE) the photocurrent spectra display both anodic (high photon energy) and cathodic photocurrent (longer wavelengths). At more anodic potentials the photocurrent spectra display only anodic photocurrent.

By assuming indirect optical transitions for passive film grown on electrodes, we plotted the anodic photocurrent yield according to equation:

$\left(I_{\mathrm{ph}} \mathrm{h} v\right)^{0.5}=\left(h v-E_{\mathrm{g}}^{\mathrm{opt}}\right)$

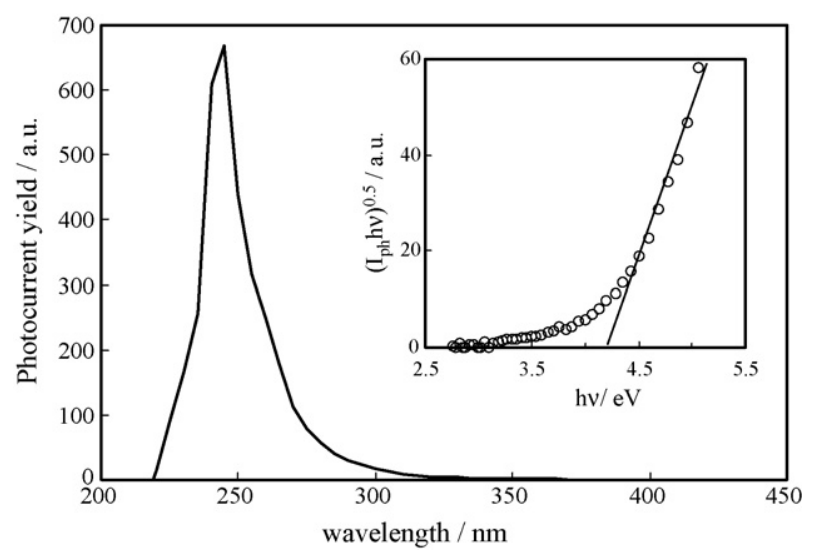

Fig. 20. Photocurrent spectrum relating to $\mathrm{Mg}$ after mechanical treatment and anodizing in $0.1 \mathrm{M} \mathrm{NaOH}$ to $0.6 \mathrm{~V}$ (MSE), recorded by polarizing the electrode at the formation potential in the same electrolyte. Inset: $\left(I_{\mathrm{ph}} h v\right)^{0.5} \mathrm{vs.} h v$ plot.

where $E_{\mathrm{g}}^{\mathrm{opt}}$ is a measure of the band gap of the corrosion layer grown in the investigated conditions.

All band gap values (see also Fig. 20) derived from anodic photocurrent spectra and according to Eq. (4), for films grown on MT electrodes after different initial treatments give an optical band gap value: $E_{\mathrm{g}}^{\mathrm{opt}}=4.25 \pm 0.1 \mathrm{eV}$. This band gap value agrees with the hypothesis that lower values are usually measured for hydroxides film [26] with respect to their anhydrous counterpart. Analogous findings have been reported for other $\mathrm{s}-, \mathrm{p}-$ and d-metal hydroxide passive films and corrosion layers [19]. It has been suggested in previous papers, according to Pourbaix diagram and thermodynamic considerations, that such an optical band gap value should be related to the formation of a $\mathrm{Mg}(\mathrm{OH})_{2}$ phase. The results of the XPS analysis reported above strongly support such an interpretation.

According to XPS and PCS data it seems reasonable to assume that the structure of initial films formed on Mg by immersion of MTE in aqueous solutions consists of a non-compact duplex layer with a thick external porous layer of hydroxide of composition near to $\mathrm{Mg}(\mathrm{OH})_{2}$, having a band gap value around $4.25 \mathrm{eV}$, which may cover an inner very thin $(<3 \mathrm{~nm})$ oxide or oxy-hydroxide layer of larger band gap, but sufficiently thin to allow direct electron tunnelling from the $\mathrm{Mg}$ Fermi level to the electrolyte conduction band (see Fig. 21a).

In the case of thicker surface layers formed by ageing at $80^{\circ} \mathrm{C}$ in $0.1 \mathrm{M} \mathrm{NaOH}$, the internal threshold value $(2.15 \pm 0.1 \mathrm{eV})$ would suggest a location of the Mg Fermi level near to the midgap of the hydroxide layer $\left(E_{\mathrm{g}}=4.25 \mathrm{eV}\right)$ in agreement with the schematic diagram reported in Fig. 21b and the insulating behaviour of $\mathrm{Mg}(\mathrm{OH})_{2}$ layer evidenced by the photocurrent versus potential plots (for $h v \geq E_{\mathrm{g}}^{\mathrm{opt}}$ ) showing both anodic and cathodic photocurrents for electrode potentials more positive or negative with respect to the inversion photocurrent potential

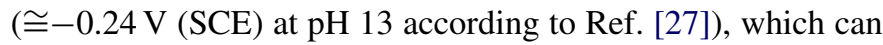
be assumed as a rough estimate of the flat band potential, $V_{\mathrm{FB}}$, for insulating oxides.

In Fig. $21 \mathrm{~b}$ a flat band potential of $-0.30 \mathrm{~V}$ (SCE) has been assumed for insulating $\mathrm{Mg}(\mathrm{OH})_{2}$ layers at $\mathrm{pH} 14$, once the value estimated at $\mathrm{pH} 13$ has been corrected in agreement with the 
(a)

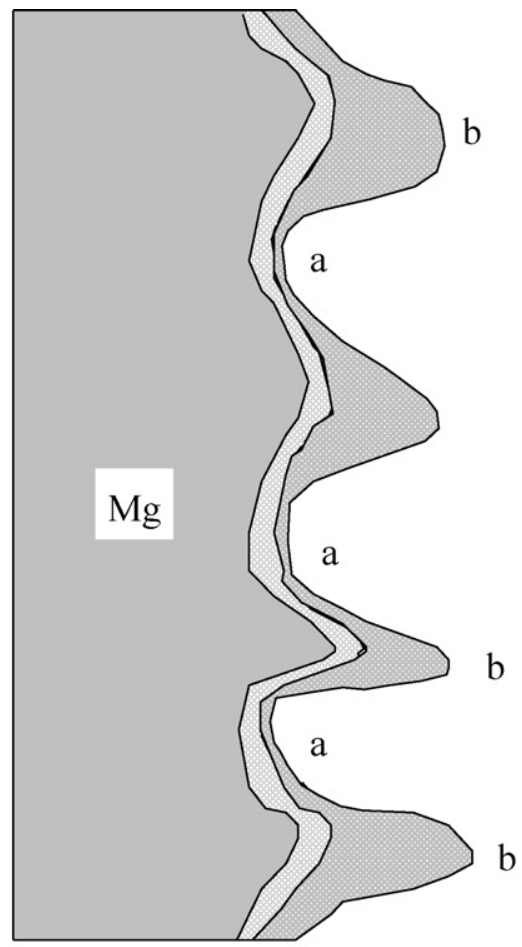

(b)

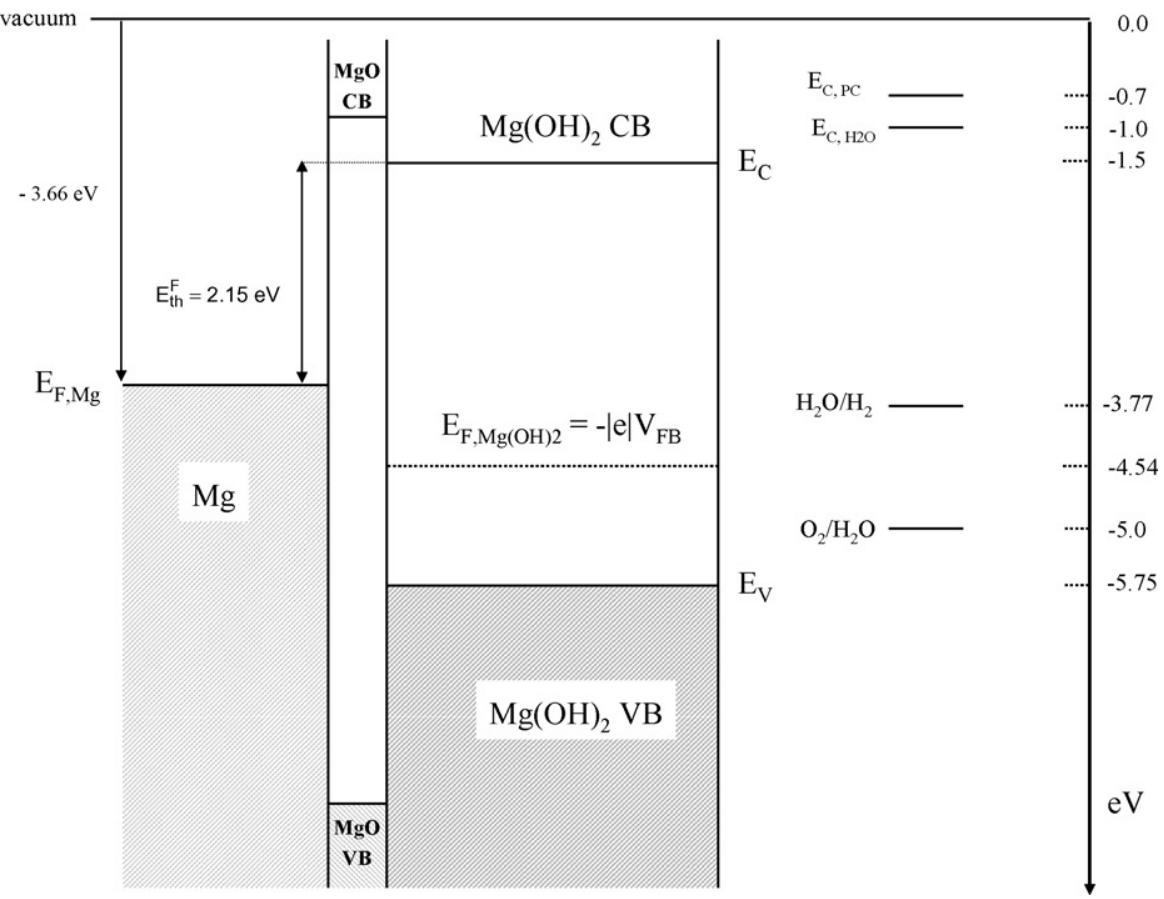

Fig. 21. (a) Representation of Mg/passive film/electrolyte interface. (a) Thin $\left(d_{\text {film }} \leq 30 \AA\right.$ ) oxide region where external photoemission occurs. (b) Thick $\left(d_{\text {film }}>30 \AA\right)$ oxide region where internal photoemission occurs. (b) Schematic diagram of characteristic energy levels (with respect to vacuum) at metal/oxide/hydroxide/electrolyte interfaces for $\mathrm{Mg}$ electrodes mechanically treated after immersion in solution. $E_{\mathrm{C}, \mathrm{PC}}$ and $E_{\mathrm{C}, \mathrm{H}_{2} \mathrm{O}}$ are the estimated energy level of propylene and water bottom conduction band, respectively.

usual dependence of $V_{\mathrm{FB}}$ observed for semiconducting or insulating oxide/electrolyte interface. According to the scheme of Fig. 21b, by illuminating $\mathrm{Mg}(\mathrm{OH})_{2}$ layers with photons having energy higher than the optical band gap $(h v \geq 4.25 \mathrm{eV})$, anodic $\left(U_{\mathrm{E}}>V_{\mathrm{FB}}\right)$ or cathodic photocurrent $\left(U_{\mathrm{E}}<V_{\mathrm{FB}}\right)$ is detected depending on the direction of electric field inside the insulat- ing hydroxide. As for the possible electrochemical processes at the hydroxide/electrolyte interface, a water reduction (cathodic) or oxidation (anodic) process can be assumed according to the scheme of Fig. 21b. In absence of further information a possible photoassisted dissolution process of the hydroxide layer cannot be excluded a priori. In any case, in presence of a steady- 
state (anodic/cathodic) photocurrent, a tunnelling process across the inner $\mathrm{MgO}$ film of photogenerated carriers (electrons/holes) must be assumed at the inner interface, according to the bilayer structure of Fig. 21b, where a band gap of $7.8 \mathrm{eV}$ has been assumed for $\mathrm{MgO}$, in agreement with the value reported in literature [21].

\section{Summary and conclusions}

A detailed investigation of the initial film grown on mechanically polished $\mathrm{Mg}$ electrodes has been carried out by in situ (PCS) and ex situ (XPS) techniques, allowing to reach a more detailed and intriguing picture of the metal/passive layer/electrolyte structure. The XPS data show the presence of an external $\mathrm{Mg}(\mathrm{OH})_{2}$ layer, whose thickness is a function of immersion time, and of an underlying ultra-thin $\mathrm{MgO}$ layer probably of constant thickness after long immersion time in neutral aqueous solution.

The PCS analysis of initial films suggests that the thicker hydroxide layer formed at room temperature is probably a porous layer allowing a direct electron photoemission process from the metal to water solution. A very thin $\mathrm{MgO} / \mathrm{Mg}(\mathrm{OH})_{2}$ layer, transparent to photoemitted electrons, is formed in some area of electrodes, allowing the electrons to reach the conduction band of water. This last condition seems to occur for initial corrosion layers grown at room temperature in water solution in a large range of $\mathrm{pH}$ values ( $\mathrm{pH}$ 6-14).

The results on $\mathrm{Mg}$ electrodes aged at higher temperature $\left(80^{\circ} \mathrm{C}\right)$ suggest that a thicker hydroxide layer not permeable to the water solution is formed on the $\mathrm{Mg}$ surface so hampering a direct external photoemission process. In this last case a Fowler photoemission process, with an internal threshold of about $2.15 \mathrm{eV}$, has been suggested. In any case after anodization at higher electrode potential the PCS data suggest the presence of a thick external layer having an optical band gap of about $4.25 \mathrm{eV}$ in agreement with the hypothesis that anodic hydroxide films display a lower optical gap with respect to their anhydrous counterpart.

The results of this study coming out from both in situ and $e x$ situ characterization of $\mathrm{Mg} / \mathrm{oxide}$ interface should help to reach a clearer picture of the corrosion behaviour of magnesium.

\section{Acknowledgement}

This work has been financially supported by Università di Palermo and CNRS-ENSCP. One of the authors (FDQ) likes to thank P\&M Curie University for providing a Visiting Professor
Fellowship during his stay at the Laboratoire de Physico-Chimie des Surfaces of ENSCP.

\section{References}

[1] J.E. Gray, B. Luan, J. Alloys Compd. 336 (2002) 88.

[2] G. Song, D. St. John, Corros. Sci. 46 (2004) 1381.

[3] E. Gulbrandsen, Electrochim. Acta 37 (1992) 1403.

[4] R. Linstrom, L.-G. Johansson, G.E. Thompson, P. Skeldon, J.E. Svensson, Corros. Sci. 46 (2004) 1141

[5] G. Song, A. Trens, D. St. John, J. Nairn, Y. Li, Corros. Sci. 39 (1997) 855.

[6] G. Song, A. Trens, D. St. John, X. Wu, J. Nairn, Corros. Sci. 39 (1997) 1981.

[7] E. Gulbrandsen, J. TaftØ, A. Olsen, Corros. Sci. 34 (1993) 1423.

[8] G. Baril, N. Pebere, Corros. Sci. 43 (2001) 471.

[9] S. Verdier, N. van der Laak, S. Delalande, J. Metson, F. Dalard, Appl. Surf. Sci. 235 (2004) 513.

[10] S. Ono, K. Asami, T. Osaka, N. Masuko, J. Electrochem. Soc. 143 (1996) L62.

[11] K. Asami, S. Ono, J. Electrochem. Soc. 147 (2000) 1408.

[12] J.H. Nordlien, S. Ono, N. Masuko, N. Nisancioglu, Corros. Sci. 39 (1997) 1397.

[13] V. Fournier, P. Marcus, I. Olefiord, Surf. Interf. Anal. 34 (2002) 494.

[14] J.H. Lee, J.H. Leun, S.G. Kim, S.Y. Park, M.J. Lee, H.J. Kim, J. Mater. Res. 18 (2003) 2895.

[15] S. Tanuma, C.J. Powell, D.R. Penn, Surf. Interf. Anal. 21 (1994) 165.

[16] J.H. Scofield, J. Electron. Spectrosc. Relat. Phenom. 8 (1976) 129.

[17] S. Piazza, A. Splendore, A. Di Paola, C. Sunseri, F. Di Quarto, J. Electrochem. Soc. 140 (1993) 3146.

[18] Yu.Ya. Gurevich, Yu.V. Pleskov, Z.A. Rotenberg, Photoelectrochemistry, Plenum Press, New York, 1980.

[19] F. Di Quarto, S. Piazza, M. Santamaria, C. Sunseri, in: H.S. Nalwa (Ed.), Handbook of Thin Films Materials, 2, Academic Press, London, 2002 (Chapter 8)

[20] F. Di Quarto, M. Santamaria, C. Sunseri, in: P. Marcus, F. Mansfeld (Eds.), Analytical Methods in Corrosion Science and Engineering, Taylor \& Francis, Boca Raton, 2006 (Chapter 18).

[21] F. Di Quarto, C. Sunseri, S. Piazza, M.C. Romano, J. Phys. Chem. B 101 (1997) 2519.

[22] R. Pandey, J.E. Jaffe, A. Barry Kunz, Phys. Rev. B (1991) 9228.

[23] J. O’M Bockris, S.U.M. Khan, Surface Electrochemistry, Plenum Press, New York, 1993, p. 78.

[24] P. Han, D.M. Bartels, J. Phys. Chem. 94 (1990) 5824.

[25] (a) R. Jaksic, in: P. Delahay, C.W. Tobias (Eds.), Advances in Electrochemistry and Electrochemical Engineering, 8, Wiley Interscience, New York, 1970, p. 314 ;

(b) K. Izutsu, Electrochemistry in Nonaqueous Solutions, Wiley-VCH, Weinheim, 2002, p. 242;

(c) Yu.Ya. Gurevich, Yu.V. Pleskov, Z.A. Rotenberg, Photoelectrochemistry, Plenum Press, New York, 1980, p. 71.

[26] M. Santamaria, E. Adragna, F. Di Quarto, Electrochem. Solid State Lett. 8 (2005) B12.

[27] L. Anicai, R. Masi, M. Santamaria, F. Di Quarto, Corros. Sci. 47 (2005) 2883. 